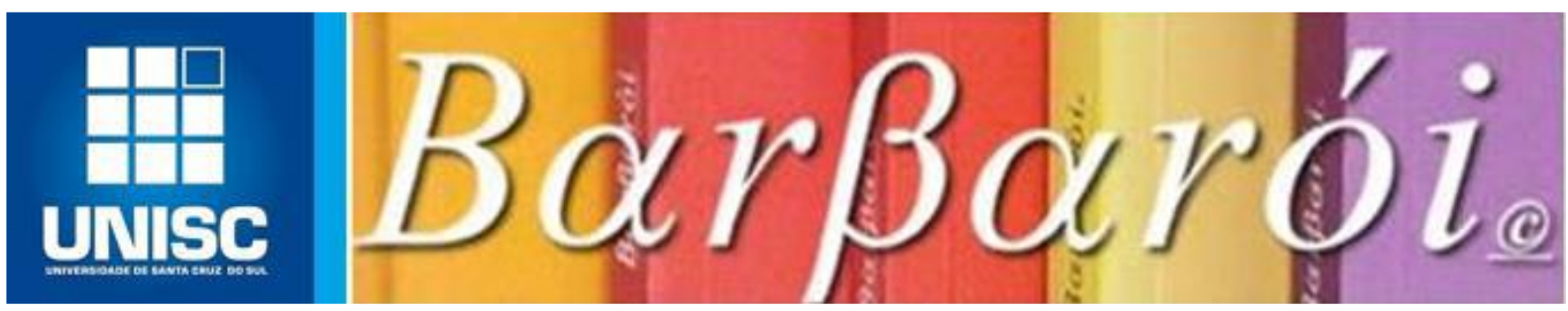

\title{
O TRABALHO INFANTOJUVENIL E A AUSÊNCIA DE DADOS: PERCEPÇÃO DA REDE DE PROTEÇÃO
}

\author{
DOI: http://dx.doi.org/10.17058/barbaroi.v0i57.15412 \\ $*$
}

\author{
Ana Cristina Serafim Silva \\ Universidade Federal do Tocantins - UFT - Brasil \\ Raimara Pereira Lourenço Duarte \\ Universidade Federal do Tocantins - UFT - Brasil

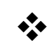

\section{Resumo}

Este artigo tem como objetivo identificar as características do trabalho infantojuvenil a partir da rede de proteção dos direitos das crianças e adolescentes. Participaram da pesquisa 35 atores sociais que atuam na Rede de proteção dos direitos da criança e do adolescente de uma cidade mediana na região central do Tocantins. Utilizou-se de um questionário composto por questões abertas e fechadas e para análise dos dados, a Análise Temática de Bardin. A partir da análise, a maioria dos atores sociais respondeu que a instituição em que atuavam não tinha dados sobre o trabalho infantojuvenil, apenas dois afirmaram que tinham registro de trabalho infantojuvenil; no entanto, quase todos os atores sociais entrevistados já viram ou têm conhecimento de crianças e adolescentes em situação de trabalho. Um dado que chama a atenção é que a maioria dos atores sociais considera o trabalho infantojuvenil bom, como dignificante e que possibilita as crianças e adolescentes criarem responsabilidades, contanto que não interfira nos estudos e não ofereça riscos à saúde.

Palavras-chave: Trabalho infantojuvenil. Rede de Proteção. Direitos da Criança e do Adolescente.

\section{Introdução}

Este artigo tem como objetivo identificar as características do trabalho infantojuvenil a partir da rede de proteção dos direitos das crianças e adolescentes, de forma a identificar as atividades de trabalho e os setores produtivos que empregam crianças e adolescentes, como também enfatizar a relação existente entre trabalho infantojuvenil e suas implicações. Segundo o levantamento da Pnad Contínua (2017), o Brasil tem cerca de 2,7 milhões de crianças e adolescentes em situação de trabalho nas suas piores formas e o Tocantins tinha 21.278. Apesar 
de vir diminuindo ao longo dos anos, esse número ainda é alto, visto o Brasil contar, atualmente, com três dispositivos que proíbem o trabalho realizado por crianças e regulamentam o trabalho realizado por adolescentes (a partir dos 14 anos na condição de aprendiz), são eles: a Constituição Federal do Brasil de 1988, o Estatuto da Criança e do Adolescente (ECA) e a Consolidação de Leis Trabalhistas (CLT).

Historicamente, o trabalho infantojuvenil sempre esteve presente, mas ele assume formas diferentes de acordo com a formação social vigente. A princípio adquiriu caráter formativo e necessário, de forma a atender às necessidades da família e do próprio grupo familiar, até assumir um caráter exploratório com o surgimento do capitalismo, que introduz o pressuposto da exploração, visto que sua expansão e consolidação se baseia no uso abusivo e degradante dessa mão de obra (ARIÈS, 1995; LIRA, 2016; PILLOTI; RIZZINI, 2009). É sob os pressupostos do capitalismo que o trabalho infantojuvenil tem assumido dimensões maiores, mais perversas e sob um maior nível de exploração.

Diversos autores (ALBERTO, 2012; CAMPOS; ALVERGA, 2001; LIRA, 2016) acrescentam que há também uma forte presença de elementos culturais em torno do trabalho infantojuvenil em que se faz disseminar uma ideologia na crença indeterminada na dignidade advinda do trabalho e uma suposta socialização pelo trabalho, dirigida principalmente, à infância da classe trabalhadora e pobre. Foi sob o pressuposto da tal dignidade do trabalho que se construiu uma variedade de mitos na sociedade, que legitimaram a existência do trabalho infantojuvenil, em que há um destaque para "é melhor a criança trabalhar do que roubar”, “o trabalho dignifica o homem", "é melhor trabalhar do que ficar na rua", "o trabalho da criança ajuda a família”, entre outros, que incidem majoritariamente na infância pobre (VERONESE; CUSTÓDIO, 2013).

Para Campos e Alverga (2001), as próprias famílias, crianças e sociedade concebem o trabalho como dignificante. Ainda de acordo com os autores, essa concepção deriva tanto de uma visão classista em que incidia sobre o trabalho manual um status de indignidade, por isso, não pertencente à nobreza, e se manifesta num instrumento de divisão e opressão de classes, cabendo aos desvalidos os trabalhos manuais e aos nobres o trabalho intelectual, como também deriva de uma ética do trabalho originária da moral puritana, inferida pela doutrina protestante, em virtude do pecado, que via no trabalho a possibilidade e a disciplina necessária e inquestionável para regular, controlar e frear o espírito voluntarioso dos jovens. A implicação dessa e de outras crenças foi, ao longo do tempo, contribuindo para o processo de naturalização 
do emprego de crianças e adolescentes em diversos setores do trabalho, sob a pretensa crença de que se emprestaria a dignidade necessária.

Aliado a essas crenças, foi se construindo um conjunto de preconceitos e representações negativas sobre crianças e adolescentes pobres, que se naturalizaram, inclusive nas políticas públicas de enfrentamento à pobreza e ao trabalho infantojuvenil e nos discursos jurídicos durante a história do Brasil, que, no primeiro instrumento de lei específico para crianças, o Código de Menores de 1927, propunha um projeto de higienização dos espaços públicos, tendo em vista a disciplinarização para o trabalho, considerando uma infância perigosa, marginal e com valores morais corrompidos (ALBERTO, 2012; FALEIROS; FALEIROS, 2008; PILLOTI; RIZZINI, 2009; SILVA, 2018). A solução para salvar a criança e o adolescente desse ambiente considerado perigoso, seria através do trabalho.

O Estado regulamentou a exploração da mão de obra infantojuvenil ao adotar uma formação para o trabalho ao longo do tempo. Foram várias as propostas, desde as Santas Casas de Misericórdia com as Rodas dos Expostos, a Casa de Educandos e Artífices, os Institutos e Patronatos Agrícolas, Escolas Profissionais, Escolas Corretivas durante o período republicano, Escola de Aprendizes e Artífices, entre outras. Todas foram políticas implementadas para a infância e adolescência brasileira pobre, considerados desvalidos ou abandonados. Mesmo que tivessem família, se esta não atendesse à moral e aos bons costumes da sociedade, perdiam o poder familiar e os filhos eram colocados em uma das instituições da época e tinham como formação o isolamento/recolhimento em instituições fechadas e a educação pelo e para o trabalho, com vistas à exploração da mão de obra desqualificada e gratuita (PILLOTI; RIZZINI, 2009).

Inclusive, no Brasil, no início do século passado, na década de 1920, era comum nos processos do Juízo de Órfãos e no Juizado de Menores “a colocação familiar" que consistia no recrutamento em asilos de meninas para o serviço doméstico em casa de terceiros (RIZZINI, 2008). A exigência imposta à família é que esta deveria assegurar à criança vestimenta, alimentação, educação e depositar por conta do trabalho da menina uma quantia na caderneta de poupança em seu nome. Era comum a ocorrência de fugas porque normalmente as crianças exploradas sofriam maus-tratos e abusos sexuais nesses domicílios. Tal política existiu até a década de 1980 e era administrada por Fundações Estaduais de Bem-Estar do Menor (RIZZINI, 2008).

O que se observa é que, nas políticas dirigidas à infância, sempre houve uma prevalência da necessidade do controle da população pobre, vista como perigosa. Para Pilloti e Rizzini 
(2009), manteve-se o abismo infranqueável entre infâncias privilegiadas e menores marginalizados, e todas as políticas propostas, além de reforçar esse abismo, configuraram-se como assistencialistas, destinadas a compensar a ausência de uma política social efetiva, capaz de proporcionar condições equitativas de desenvolvimento para crianças e adolescentes de qualquer classe social.

Para Silva e Alberto (2016) há formas diferenciadas de se ver e vivenciar a infância no Brasil. Para alguns é possível viver a infância e adolescência como proposto nos documentos legais, mas para outros, principalmente pobres, não há uma demarcação simbólica entre infância e adolescência, pois precisam adentrar no mundo do trabalho logo cedo. De acordo com Alberto (2002), há um processo de socialização desigual, que é pautado em classes sociais, não há uma infância e juventude igual para todos; os que pertencem às classes dominantes vivenciam um desenvolvimento prolongado, já os pertencentes às classes subalternas têm um desenvolvimento abreviado e essa forma diferenciada decorre da acentuada desigualdade social. Justamente a desigualdade social, decorrente das relações contraditórias e de interesses distintos, contribui para a inserção precoce de crianças e adolescentes no trabalho e impõe uma negação da sua condição infantil e suas implicações (ALBERTO, 2002; LIRA, 2016). Para as autoras, tal fato representa uma contradição, na medida em que há a supressão da infância na realidade concreta através da inserção no mundo do trabalho, há também uma formalização de medidas protetivas que se expressam no seu conteúdo legal.

Apesar de ter um consenso em torno da pobreza como causa do trabalho infantojuvenil, diversos autores (ALBERTO, 2012; ALBERTO; YAMAMOTO, 2017; CAMPOS; ALVERGA, 2001; LIRA, 2016) apontam que o trabalho infantojuvenil não pode ser explicado somente por esse prisma, mas por um conjunto de fatores, tais como os aspectos econômicos, o sistema jurídico, aspectos culturais e ideológicos, questões de ordem política, o baixo acesso à educação, a ineficácia e/ou inexistência de políticas públicas e fortalecimento e proteção à família, entre outros fatores, contribuem para a inserção precoce.

Adota-se, neste artigo, o termo trabalho infantojuvenil, em que se entende o desempenho de atividades econômicas e de sobrevivência, com ou sem a finalidade de lucro, podendo ser remunerado ou não, realizadas por crianças e adolescentes com idade inferior a 16 anos, considerando a condição de aprendiz a partir dos 14 anos, conforme prevê o $\operatorname{Art}^{\circ} 7^{\circ}$ da Constituição Federal de 1988 e o Art $^{\circ} 60$ do ECA. O Fórum Nacional de Prevenção e Erradicação do Trabalho Infantil - FNPETI (2018) destaca que toda atividade desempenhada por adolescente trabalhador, que por sua natureza ou pelas circunstâncias em que é executada, 
possa prejudicar o seu desenvolvimento físico, psicológico, social e moral, enquadra-se como trabalho infantojuvenil e é proibida para pessoas abaixo de 18 anos de idade.

Atualmente a proibição ao trabalho infantojuvenil está prevista em legislação internacional e nacional. No Brasil, a partir da Constituição Federal de 1988, a infância e adolescência passaram a ser reconhecidas, consagradas no artigo 227, em que se assegura a proteção, com absoluta prioridade, o direito à vida, saúde, ao respeito, à liberdade, à alimentação, à educação, ao lazer, à profissionalização, à cultura, à dignidade, à liberdade e à convivência familiar e comunitária, além de colocá-las a salvo de toda forma de negligência, opressão, crueldade, exploração, violência e discriminação.

A consolidação do artigo 227 se faz através do Estatuto da Criança e Adolescente (ECA), Lei 8.069/1990, que se propõe uma ruptura com toda a legislação menorista anterior, superando o enfoque opressor e reconhecendo todas as crianças e adolescentes como sujeitos de direitos, e que em função de sua condição peculiar de pessoas em desenvolvimento precisem de uma proteção integral, cabendo a responsabilidade ao Estado, sociedade e família. O ECA vem regulamentar através dos artigos 60 a 69 a proibição do trabalho infantojuvenil e a proteção ao adolescente trabalhador, conforme consta também na Constituição Federal.

A Consolidação das Leis Trabalhistas - CLT (BRASIL, 1943), entre os artigos 402 e 441, estabelece as condições para a atuação profissional de jovens, a partir de 14 anos até os 17 e inclui no seu texto a Lei de Aprendiz (10.097/2000) e o decreto federal 5.598/2005.

Em âmbito mundial, vários tratados e convenções, tais como a Convenção Internacional dos Direitos da Criança e as Convenções da OIT, Convenção 138 que dispõe sobre a idade mínima para admissão ao trabalho e a Convenção 182 que versa sobre as piores formas de trabalho infantojuvenil, foram ratificadas pelo Brasil. Com isso, o país assumiu o compromisso de adotar medidas imediatas que garantissem a proibição e a eliminação das piores formas de trabalho infantojuvenil. Como medida de cumprimento, o Brasil elaborou a Lista das Piores Formas de Trabalho Infantil, a Lista TIP, através do Decreto ${ }^{\circ}$ 6.481/2008, em que consta, como piores formas, o trabalho infantojuvenil na agricultura, doméstico, na produção e tráfico de drogas, informal urbano, na exploração sexual comercial, no comércio de reparação, entre outros.

É preciso visualizar o trabalho infantojuvenil atrelado às suas implicações no desenvolvimento da criança e do adolescente e como uma transgressão a um direito garantido. Entre as implicações, há destaque para os aspectos físicos, psíquicos, escolares, sociais, ergonômicos, químicos, perspectivas de futuro, entre vários outros. 
Diversos autores (ALBERTO, 2012; ALBERTO; YAMAMOTO, 2017; CAMPOS; ALVERGA, 2001; LIRA, 2016; SILVA, 2018; SILVA; FONSECA, 2017; SILVA; PEREIRA, 2013) têm apontado para as implicações físicas que o trabalho infantojuvenil ocasiona, submetidos a jornadas extensas e tendo que lidar com tarefas que muitas vezes desafiam os limites físicos da idade, ao escalar, arrastar móveis, carregar peso, manusear fogo no preparo de alimentos, postura inadequada que podem lesionar a coluna, que ocasionam danos ergonômicos irreversíveis pelo carregamento de peso em excesso, riscos de acidentes com objetos perfuro-cortantes, quedas relacionadas a pisos molhados, entre outros.

Há ainda as implicações químicas com a exposição prolongada à radiação solar, chuva, vento, umidade, intoxicação pelo uso de produtos químicos na agricultura, no trabalho infantojuvenil doméstico, no comércio de reparação, em oficinas e lava a jatos, nestes, se faz uso excessivo de produtos corrosivos, lubrificantes, manuseio de combustível, exposição ao monóxido de carbono, dióxido de enxofre, entre outros produtos que, quando em contato com a pele da criança e adolescente, provocam queimaduras, ferimentos, doenças respiratórias, envelhecimento precoce, câncer de pele, desidratação, entre outros (ALBERTO et al., 2010; ALBERTO; SANTOS, 2011; LIRA, 2016; SILVA, 2018; SILVA; FONSECA, 2017; SILVA; PEREIRA, 2013).

Ocasiona danos psicológicos e sociais ao ficar exposto a diversas formas de violência e negação de direitos, assédio moral, abusos físicos e sexuais, socialização desviante, adultização precoce, excesso de cobranças e as dificuldades em atendê-las, ao ficar responsável por uma atividade, comprometendo o desenvolvimento afetivo e cognitivo e provocar a sensação de tempo perdido ou ter perdido a infância (ALBERTO, 2002; ALBERTO et al, 2010; ALBERTO; SANTOS, 2011; LIRA, 2016; SILVA, 2018; SILVA; FONSECA, 2017; SILVA; PEREIRA, 2013). Não se trata apenas do tempo em que se dedica ao trabalho que rouba o tempo da infância, mas também o tipo de trabalho que se caracteriza por ser enfadonho, repetitivo, precoce, pesado e que lhes retira as energias do corpo, cognitivas, motoras para o brincar e o aprender.

Lira (2016) observou em pesquisa realizada que as crianças, principalmente as de menor idade, tendem a driblar a condição de roubo do tempo para brincar, brincando em serviço, transformando o trabalho em brincadeira e os instrumentos de trabalho em brinquedos, e em decorrência desta "transgressão" muitos afirmam terem sofrido acidentes no momento em que brincavam no trabalho. Alberto et al. (2005) demonstram, através de estudo, que as crianças e adolescentes são mais vulneráveis a doenças e acidentes de trabalho em decorrência da 
imaturidade e inexperiências, próprias da idade. Atividades de trabalho realizadas por crianças e adolescentes, ainda que leves, podem ser consideradas inadequadas e de risco para a saúde física e mental.

Uma das implicações que mais afetam crianças e adolescentes trabalhadores é com relação à escolarização. A maioria das pesquisas sobre trabalho infantojuvenil (ALBERTO, 2002; ALBERTO et al., 2010; ALBERTO; SANTOS, 2011; LIRA, 2016; SILVA, 2018; SILVA; FONSECA, 2017; SILVA; PEREIRA, 2013) identifica uma piora no rendimento escolar, dificuldade de concentração, abandono, reprovação e defasagem escolar. A execução da atividade de trabalho é exaustiva para o corpo de uma criança e/ou adolescente, demanda muito tempo, esforço físico, aliado ao cansaço, sono, por ter que cumprir uma dupla jornada, ao ter que conciliar a escola e o trabalho, repercute em dificuldades que remetem à falta de concentração e dificuldade de aprender, impedindo-os de desenvolver plenamente seu potencial, sobretudo, no âmbito escolar, além de ferir o direito à educação garantido no ECA.

O baixo acesso à educação é um problema que vai repercutir futuramente na vida de crianças e adolescentes. Segundo Dias e Araújo (2013), o baixo acesso se estende também às famílias dessas crianças e adolescentes, que quando privadas de escolaridade, durante a infância e adolescência, têm uma percepção de que o trabalho é um elemento de transmissão de saberes em detrimento das ruas, enquanto a escola é vista como necessária somente para conhecimentos básicos, da leitura, escrita e operações matemáticas simples. O que se percebe é que há uma repetição de valores que estão arraigados na cultura, aliado a todas as condições de desigualdade social e à baixa instrução; quando adultos, essas crianças e adolescentes trabalhadores não conseguirão empregos que permitam uma vida digna sem comprometer o desenvolvimento e a inserção de seus filhos no trabalho.

De acordo com Lira (2016), as implicações do trabalho infantojuvenil interferem e violam direitos fundamentais, como previsto nos instrumentos legais, sobretudo o ECA, entre eles, o direito à saúde, em virtude das doenças e acidentes por ocasião do trabalho, o direito à liberdade, à dignidade e ao respeito, muitas vezes negado ao ter que trabalhar e sofrer desde assédios a violências, o direito à convivência familiar e comunitária, pela ausência por estar em situação de trabalho, o direito à educação, pelo impedimento de acesso e permanência na escola que ocasiona um baixo rendimento, o direito à profissionalização, no tempo certo e nas condições adequadas que possibilitarão melhores condições de vida e de emprego futuramente, e o direito à proteção, que está relacionado à proibição da exploração da sua força de trabalho e o amparo pela sua condição de ser sujeito em condição peculiar de desenvolvimento. 
O ECA modifica as políticas públicas relacionadas à infância e adolescência, que sai da alçada de Juízes de Menores e atribui a responsabilidade pela defesa dos direitos das crianças e adolescentes ao Estado, à sociedade e à família. Inova ao oferecer procedimentos e medidas distintas por suas necessidades e especificidades, procurando estabelecer estratégias e metodologias que visem à proteção dos valores sociais estabelecidos em Lei. Ele institui uma nova política de atendimento aos direitos de crianças e adolescentes, no seu artigo 86, que deve atuar no formato em rede, com instituições e atores sociais articulados e integrados na garantia e proteção dos direitos desses sujeitos (SILVA; ALBERTO, 2019).

Entre as estratégias, temos o Sistema de Garantia de Direitos (SGD) da criança e do adolescente e uma rede institucional, com base no artigo 86 do ECA (OLIVEIRA, 2010). O SGD se constitui na integração e articulação de instituições públicas governamentais e da sociedade civil, como mecanismos de promoção, defesa e controle para efetivar os Direitos Humanos da criança e do adolescente. Segundo Silva e Alberto (2019), o desafio para a materialização das políticas públicas e garantia dos direitos desses sujeitos passa pelo atendimento das políticas numa perspectiva de rede. Rede é vista como um tecido de relações que são estabelecidas em virtude de uma finalidade em comum e se interconectam por ações em conjunto (RIZZINI, 2006). A rede é uma ferramenta das políticas públicas cujo objetivo é proteger os direitos de crianças e adolescentes, formada pelos atores sociais das várias instituições engajadas no mesmo objetivo (SILVA; ALBERTO, 2019; RIZZINI, 2006). Uma rede integrada e articulada deve estar ligada a todos os setores, desde saúde, educação, justiça, assistência social, segurança pública, conselhos a nível municipal, estadual e federal, que oferecerá um atendimento completo à criança, ao adolescente e à sua família.

Em pesquisa realizada, Silva e Alberto (2019), encontraram dados em que a rede tem tido muitas dificuldades para ser uma ferramenta das políticas públicas, no que tange à proteção dos direitos das crianças e adolescentes, em que demonstrava falta de conhecimentos sobre a legislação atual que regulamenta a infância e adolescência, falta de articulação com as instituições que compõem a rede, desconhecimento com as orientações e normas da política de atendimento à infância e adolescência, as quais trazem as diretrizes sobre o funcionamento, e se encontram alijadas dos debates na construção de uma política intersetorial de prevenção da violação dos direitos e de proteção das crianças e dos adolescentes.

Desde 2013, a política de enfrentamento ao trabalho infantojuvenil no Brasil se faz através do Serviço de Convivência e Fortalecimento de Vínculos (SCFV), atendendo crianças e adolescentes com idades entre 6 e 15 anos, referenciados no Centro de Referência da 
Assistência Social (CRAS). Esse serviço tem como objetivo o complemento do trabalho social realizado com as famílias e prevenir situações de risco social (BRASIL, 2014).

No entanto, é através do Centro de Referência Especializado da Assistência Social (CREAS), que tem por objetivo o trabalho social com famílias e indivíduos em situação de risco pessoal e social por violação de direitos, através do Serviço Especializado em Abordagem Social (SEAS), que identifica a família ou indivíduo que teve seu direito violado, principalmente relacionado à incidência de trabalho infantil, exploração sexual de crianças e adolescentes, situação de rua, entre outros, fazendo o mapeamento, atendimento e intervenção no território, visando ao enfrentamento e superação das violências vivenciadas (NASCIMENTO, 2020). Ainda de acordo com Nascimento (2020), ao SEAS cabe identificar as demandas do território, mapear e realizar diagnósticos das reais necessidades, de forma a promover melhorias para a população assistida, melhoria nas condições de vida, bem como assegurar o acesso dessa população aos direitos e serviços socioassistenciais.

Através do Serviço de Proteção e Atendimento Especializado a Famílias e Indivíduos (PAETI), que é o serviço de apoio, orientação e acompanhamento a famílias com um ou mais de seus membros em situação de ameaça ou violação de direitos, de forma a preservar e fortalecer os vínculos familiares, que as crianças e adolescentes identificados em situação de trabalho passam a ser atendidos. Esse serviço se articula com as atividades e atenções prestadas às famílias nos demais serviços socioassistenciais, entre eles o SCFV do CRAS (BRASIL, 2014). Ao PAEFI cabe garantir de imediato a inclusão da família e seus membros nos serviços socioassistenciais e/ou em programas de transferência de renda, de maneira a qualificar a intervenção e restaurar o direito. As crianças e adolescentes identificados pelo SEAS são, então, encaminhadas para o SCVF.

\section{Aspectos metodológicos}

Este é um estudo exploratório, de caráter qualitativo. O contexto em que se desenvolveu a pesquisa foi uma cidade de médio porte, localizada na região central do Tocantins que apresentava instituições que fazem parte do SGD. Foi feito um mapeamento e contato com todas as instituições da cidade, apenas 6 instituições concordaram em participar, são elas: CMDCA, CREAS, Polícia Militar, Escolas Estaduais, Secretaria da Assistência Social e Conselho Tutelar. O agendamento do horário e do local das entrevistas foi feito de acordo com a disponibilidade do ator social e na instituição em que trabalhavam. 
Utilizou-se como técnica de coleta de dados um questionário com perguntas abertas e fechadas que versavam sobre dados sociodemográficos, a caracterização do trabalho infantojuvenil na cidade a partir dos dados da instituição e a partir da percepção dos atores sociais fora da instituição. Para análise dos dados, utilizou-se a Análise Temática de Bardin (2010). Após aplicação, foi feita uma leitura de todo o material, as perguntas abertas foram transcritas para formar um corpus, posteriormente foi realizada a tabulação, que consistiu na agregação das temáticas semelhantes. Da codificação emergiram as categorias representativas dos núcleos de sentido, as categorias que surgiram foram: Caracterização do trabalho infantojuvenil e Percepção do trabalho infantojuvenil pelos atores sociais.

Para esta pesquisa, foram adotadas todas as diretrizes determinadas pela Resolução $\mathrm{n}^{\circ}$ 466, de 12 de dezembro de 2012, do Conselho Nacional de Saúde, que regulamenta a pesquisa com seres humanos, com a aprovação do projeto de pesquisa pelo Comitê de Ética em Pesquisa, sob o número CAAE 15209918.0.0000.5519.

\section{Resultados e discussão}

Responderam ao questionário 35 pessoas, sendo 23 do sexo feminino e 12 do masculino, com idade variando de 23 a 52 anos. O nível de escolaridade variava do ensino médio completo à pós-graduação. Predominou o ensino superior, contando com 29 pessoas, seguido do ensino médio, com 4 pessoas, e apenas 2 pessoas com pós-graduação. A maioria tinha graduação em Pedagogia, seguida por graduação em Letras, Matemática, Normal Superior, Psicologia, Serviço Social e Gestão Ambiental.

Desempenhavam as atividades profissionais de conselheiro tutelar (2), professor (13), inspetor (1), gestor escolar (2), coordenador pedagógico (4), sargento (2), subtenente (2), orientador educacional (1), técnico de referência (2), assistente de vigilância social (1), diretor de gestão (1), intérprete (1) e professor auxiliar (3).

Com relação à formação específica para trabalhar na infância e adolescência, a maioria dos participantes informou que somente durante a graduação, outros disseram que fizeram cursos oferecidos pelo Estado, capacitações, participação em eventos, dois responderam que foi a partir da leitura dos instrumentos legais, dois fizeram uma pós-graduação e outros informaram que não tiveram uma formação específica. Esse dado é corroborado por Silva e Alberto (2019) sobre os profissionais que integram a rede de proteção dos direitos das crianças e adolescentes que não tem uma formação específica, nem mesmo o conhecimento dos instrumentos legais, 
que implicam, por vezes, em leituras equivocadas ou errôneas no que tange aos aspectos da própria legislação, como também da implementação das políticas.

\section{Caracterização do trabalho infantojuvenil}

Com relação à caracterização do trabalho infantojuvenil, este se deu a partir dos dados que a instituição tinha, como também pela visão dos atores sociais, por terem visto ou presenciado situações em que crianças e adolescentes trabalhavam fora da instituição em que atuavam.

Ao serem questionados se a instituição em que atuavam tinha registros formais de casos de trabalho infantojuvenil, a maioria dos participantes informou que não sabia/não conhecia (20), outros (13) afirmaram que não havia dados e apenas dois atores sociais afirmaram que na instituição em que atuavam havia casos de trabalho infantojuvenil. As duas instituições eram a Secretaria de Assistência Social e o Centro de Referência Especializado de Assistência Social (CREAS)

A partir dos dados que chegaram nessas duas instituições, as crianças têm entre 6 e 10 anos de idade, trabalham tanto na zona rural quanto urbana, a maioria são afrodescendentes, e geralmente trabalham para e com a família. As atividades que desempenham são de catadores de latinha, roçar terreno, manuseio de horta e venda de picolés, geralmente recebem dinheiro e comida como forma de pagamento. Trabalham durante o dia e à noite estudam. Não têm informações sobre os riscos que as atividades causam. As famílias dessas crianças e adolescentes participam de algum programa do governo, entre eles o PAIF, SCFV, PBF. Tais achados também foram identificados por outras pesquisas (ALBERTO et al., 2010; ALBERTO; SANTOS, 2011; LIRA, 2016; SILVA, 2018; SILVA; FONSECA, 2017; SILVA; PEREIRA, 2013).

A maioria dos atores sociais atuava nas escolas estaduais da cidade, todos afirmaram não ter conhecimento sobre trabalho infantojuvenil na escola; em que pese, é no espaço da escola que tem o maior número de adolescentes, mas esta não tem dados nem sobre trabalho na situação de aprendizagem, permitido a partir dos 14 anos, mediante contrato de aprendizagem (BRASIL, 1990). Na Segurança Pública, aqui representada pela Polícia Militar também afirmaram não ter conhecimento sobre trabalho infantojuvenil. E os atores sociais que atuavam no Conselho Tutelar também informaram que na instituição não tinha dados sobre trabalho infantojuvenil da cidade. 
Presumidamente, baseado no Art. 136 do ECA que consta das atribuições do Conselho Tutelar, a fiscalização é uma dessas atribuições. Teria esta instituição a competência de atuar como órgão da política de proteção, o que remete à sua função enquanto órgão protetivo cuja função é defender e fazer valer os direitos das crianças e adolescentes, sobretudo em situações de violação de direitos. Mesmo que não explicitado nas suas atribuições, no referido documento, pelo que compete e os requisitos que tais ações exigem por parte do Conselho Tutelar, cabe a este conselho uma atuação mais proativa, não somente esperando a denúncia. A espera por denúncias constitui numa das problemáticas que enfraquece a rede de proteção dos direitos de crianças e adolescentes e ainda contraria a lei e pode determinar a responsabilização do conselheiro que omite a informação ao Ministério Público, de acordo com o art. $6^{\circ}$, da Lei 7.347/1985 e o art. 136 do ECA (RODRIGUES, 2013). Para o autor, em muitos municípios, o Conselho Tutelar se depara com situações de trabalho infantojuvenil; no entanto, não se chega aos Ministério Público do Trabalho, visto que não é feito por denúncia. Tal fato se faz obstaculizar pela naturalização do trabalho infantojuvenil frente à cultura que predomina na sociedade, aumentando a subnotificação e contribuindo para a carência de notificações.

O Conselho Tutelar juntamente com o Conselho Municipal dos Direitos da Criança e do Adolescente precisam elaborar planos de atuação, em que pese uma atuação mais proativa, como também podem elaborar um mapeamento das atividades econômicas de risco às crianças e adolescentes com base na Lista TIP, de forma a adotar estratégias de inspeção prioritária em determinados ramos de atividades econômicas com maior impacto na cidade e colocar em prática medidas educativas (RODRIGUES, 2013).

Identifica-se que somente os serviços socioassistenciais têm dados ou informações relacionadas ao trabalho infantojuvenil (BRASIL, 2014; NASCIMENTO, 2020). As políticas sociais são ferramentas que visam à proteção social, entre elas, as políticas educacionais são tratadas como políticas de Estado, universais, básicas e voltadas para todos os sujeitos. Já as políticas de assistência social têm condicionalidades e são de caráter especial, segmentadas, rompem com a universalidade ao serem dirigidas para a pobreza e atingem segmentos específicos (BEHRING; BOSCHETTI, 2011). Logo, as políticas de assistência social no Brasil são impotentes na universalização do acesso aos serviços (IAMAMOTO, 2009). Para a autora, essa particularidade das políticas de assistência social no Brasil é um dos fatores da fragilidade da parceria entre Estado e movimentos sociais, cujas lutas até possibilitam criar leis, mas a política posta em prática se desfaz perante novos determinantes históricos da questão social; quando há os ajustes orçamentários com o objetivo de reduzir despesas e cortar gastos, a política 
da assistência social é a que mais perde, e com isso o enfrentamento ao trabalho infantojuvenil também.

Para Behring e Boschetti (2011) o governo brasileiro, ao adotar as políticas de assistência social e não políticas educacionais para o enfrentamento ao trabalho infantojuvenil, opta por uma linha de ação equivocada, exatamente por não ser universalista, e elas diminuem os gastos porque são seletivas e têm condicionantes, atingem determinados segmentos da sociedade e não todos. O que implica também na atuação e responsabilização de determinadas instituições na sociedade e não de outras. Pelo estudo aqui conduzido, somente as instituições que fazem parte das políticas de assistência social tinham dados sobre o trabalho infantojuvenil, as outras políticas não têm dados, o que pode ser explicado pela forma como o governo brasileiro vem constituindo as políticas de enfrentamento ao trabalho infantojuvenil, que se apresentam fragmentárias, eventuais e descontínuas e operacionalizadas através de programas sociais.

Diversos autores (ALBERTO; YAMAMOTO, 2017; BEHRING; BOSCHETTI, 2011; IAMAMOTO, 2009) têm afirmado que as políticas voltadas para a erradicação do trabalho infantojuvenil se mostram insignificantes, com impactos reduzidos, são focalistas e compensatórias, e, desta forma, não contribuem para promover a dignidade humana de crianças, adolescentes e suas famílias que vivenciam cotidianamente a negação de direitos humanos fundamentais, tais como alimentação, educação, lazer, habitação e o direito de não trabalhar e de se fazer reconhecer como sujeitos de direitos.

Para Mioto (2008) há uma redução da atuação estatal na área social e um significativo deslocamento da responsabilidade dos serviços sociais para a sociedade e as famílias, com políticas sociais de caráter familista, cuja ideia é que a família seja capaz de assumir a responsabilidade pelo bem-estar dos seus membros; dessa forma, dissolve-se a responsabilidade coletiva da proteção social. É possível perceber, pelos dados da pesquisa, que a questão do trabalho infantojuvenil e seu enfrentamento não é responsabilidade de todos, como prevê o ECA, nem mesmo existe uma atuação em rede, conforme o Art. 86 do referido Estatuto.

Embora a maioria dos atores sociais tenha informado que a instituição em que trabalhavam não tinha dados sobre o trabalho infantojuvenil, ao serem indagados se já tinham visto crianças e adolescentes em situação de trabalho, 22 atores sociais já tinham visto, 6 afirmaram que nunca viram e 7 não responderam.

Com relação à atividade que as crianças e adolescentes desempenhavam, a maioria relatou que era a venda de produtos, desde picolé, geladinho, bolo, doces, bombons, salgados, 
entre outros produtos. Destacam-se também as atividades em bares, lanchonetes, restaurantes como garçons e ajudando a servir; atividades em estacionamentos, durantes festas e temporada de praias. Há também atividades de capinar lotes, na lavoura de cana-de-açúcar; atividades em papelaria, supermercados, nas feiras livres como entregadores, empacotadores; e atividades em oficinas de bicicleta e lava a jatos. Todas essas atividades estão presentes na Lista TIP das piores formas de trabalho infantojuvenil (BRASIL, 2008). As atividades em destaque também foram encontradas por outras pesquisas no Tocantins (SILVA, 2018; SILVA; FONSECA, 2017; SILVA; PEREIRA, 2013), em que se destacam as atividades informais de rua, com a venda de produtos os mais diversos, bem como atividades na agricultura e em lava a jatos e oficinas mecânicas.

Em uma das falas dos atores sociais chama a atenção a descrição da atividade que a criança e/ou adolescente desempenhava, "olhando carros para evitar roubo" (A33). As crianças e adolescentes são os responsáveis por guardar o veículo para evitar roubos, claramente se percebe o absurdo da afirmação e uma espécie de desresponsabilização da sociedade para com esses sujeitos, conforme Mioto (2008). Se é necessário alguém para cuidar do veículo para impedir roubos, é uma atividade que põe em risco a vida de crianças e adolescentes.

Com relação aos locais e à frequência, a maioria dos atores sociais informou que era frequente a presença de crianças e adolescentes trabalhando, várias, nas ruas, nas praças, nas feiras, nas praias, nas festas, nos bares, lanchonetes, restaurantes, papelaria, oficinas mecânicas, lava a jatos, lotes e supermercados. Com relação às idades, a maioria informou que as crianças e adolescentes aparentavam ter entre 11 e 16 anos de idade, outros ainda afirmaram que tinham entre 6 e 10 anos. Conforme as legislações que regulamentam a infância e adolescência e o trabalho no Brasil, Constituição Federal de 1988, ECA, Convenção 138, CLT, é proibido o trabalho de crianças e adolescentes antes dos 16 anos, exceto na condição de aprendiz, a partir dos 14 anos, o que não é o caso dos dados desta pesquisa, os adolescentes não se caracterizavam por desempenho de atividades na condição de aprendiz.

Quando perguntado sobre os riscos que as atividades ofereciam às crianças e adolescentes em situação e trabalho, 13 dos 22 atores que viram crianças e adolescentes trabalhando responderam que a atividade oferecia risco sim, entre os riscos, acidentes e atropelamento, de ser roubada, violentada por estarem desacompanhadas, estupros, contato com pessoas estranhas, contato com as drogas. Silva (2009) também traz pesquisa que aborda os riscos de se estar em situação de rua e o uso de drogas, a partir do contato com outras pessoas. Diversas pesquisas (ALBERTO, 2002; ALBERTO et al., 2010; ALBERTO; SANTOS, 2011; 
LIRA, 2016; SILVA, 2018; SILVA; FONSECA, 2017; SILVA; PEREIRA, 2013) também abordam sobre os riscos e as implicações do trabalho infantojuvenil de crianças e adolescentes, desde os riscos de atropelamento, por serem mais desatentas e terem que fazer várias atividades ao mesmo tempo, ao misturar trabalho e brincadeira, os riscos de assédios por pessoas mais velhas, entre outros. Os riscos citados se referiam somente aos riscos sociais, psicológicos, emocionais; não foram abordados por ninguém os riscos físicos, químicos, ergonômicos e educacionais. Os outros 9 atores sociais informaram que as atividades não ofereciam risco algum, mesmo o trabalho sendo no período noturno, em bares, restaurantes e festas.

Percebe-se, pela descrição das atividades, que pela sua natureza ou mesmo pelas circunstâncias em que se desenvolvem, elas trazem implicações para a saúde e o desenvolvimento moral, social e psicológico das crianças e adolescentes.

\section{Percepção do trabalho infantojuvenil pelos atores sociais}

Com relação à percepção que os atores sociais tinham do trabalho infantojuvenil, a maioria afirmou que achavam bom, positivo, desde que não atrapalhasse os estudos e não trouxesse riscos à saúde das crianças e adolescentes. As falas a seguir dão exemplos: A31: "Se for um adolescente com mais de 13 anos e não prejudicar os estudos, traz dignidade". A32: "Desde que não atrapalhe no processo formativo educacional vejo como uma forma de preparação para a vida profissional". A33: "Normal, se for digno, sem exploração de excesso da criança, desde cedo tem que ter responsabilidade".

Observa-se que as falas estão imbuídas da questão ideológica do trabalho como formador, como dignificante do homem, do trabalho que traz responsabilidade, conforme as legislações anteriores e toda a construção da história das políticas para a infância e adolescência pobre no Brasil, que encontram respaldo em diversos autores (ALBERTO, 2012; ALBERTO; YAMAMOTO, 2017; CAMPOS; ALVERGA, 2001; FALEIROS; FALEIROS, 2008; PILLOTI; RIZZINI, 2009; LIRA, 2016).

O enfrentamento ao trabalho infantojuvenil passa também por uma mudança ideológica da própria sociedade e inclusive das famílias dessas crianças e adolescentes (CAMPOS; ALVERGA, 2001). É necessário um rompimento com as legislações anteriores (SILVA; ALBERTO, 2016) e um trabalho educativo inclusive com os atores sociais que atuam nas instituições de proteção dos direitos das crianças e adolescentes, de que a educação pode garantir um futuro melhor e não o trabalho infantojuvenil. Diversas pesquisas (ALBERTO, 2002; ALBERTO et al., 2010; ALBERTO; SANTOS, 2011; LIRA, 2016; SILVA, 2018; 
SILVA; FONSECA, 2017; SILVA, ALBERTO, 2016; SILVA; PEREIRA, 2013) têm identificado que o trabalho infantojuvenil reproduz intergeracionalmente a pobreza. Essas crianças e adolescentes têm pais que, além de não terem estudos, valorizam, diante da necessidade imediata, o trabalho em detrimento da escolaridade e de ser visto como um antídoto à marginalidade. Tal concepção também é defendida pela sociedade como um todo.

Ademais, nenhuma forma de trabalho que esteja em desacordo com a legislação contribui para a inserção da criança e do adolescente no mundo do trabalho, não possui um caráter de formação técnica e impede o acesso da criança e/ou adolescente a um aprendizado que o levará à inserção no mercado de trabalho, quando adulto. A inserção precoce no mercado de trabalho, no máximo, vai levar a trabalhos exploratórios e com baixa remuneração; não conseguindo competir por empregos mais qualificados, implica também no comprometimento do processo educacional, traz danos ao desenvolvimento físico, mental, social, afetivo, moral e contribui para aumento da exploração e abusos, gera mão de obra desqualificada, serve para aumentar o exército de reserva, tirando postos de trabalho de adultos e contribuindo para futuramente não conseguir um emprego digno.

Outro dado encontrado foi com relação às ações desenvolvidas pelas instituições no enfrentamento ao trabalho infantojuvenil; boa parte informou que trabalham com palestras e conscientização e sobre a importância da escola. Muitos também responderam não ter conhecimento da temática na instituição em que atuavam.

É necessário atentar para o importante papel da educação na futura capacitação, socialização e abertura de novos horizontes para essas crianças e adolescentes. Embora as políticas educacionais não tenham a capacidade de erradicar o trabalho infantojuvenil e nem de resolver os problemas da fome, desemprego e desigualdade social, são ferramentas importantes de transformação social (ALBERTO, 2012; ALBERTO; YAMAMOTO, 2017), a começar pela construção e reprodução do ser social, capaz de produzir transformações.

Para Sartori e Garcia (2012) a única forma de provocar uma mudança nas políticas de enfrentamento ao trabalho infantojuvenil seria através de uma interdependência entre programas de transferência de renda e escola, caso contrário, permanecerá uma parte da sociedade cada vez mais pobre e sem perspectiva de quebrar esse ciclo de reprodução da pobreza. Para as autoras, ao adentrar no mundo do trabalho, as crianças e adolescentes não garantem à sua família melhoras significativas na qualidade de vida, pois o que ganham é muito pouco, visto se tratar de trabalhos na informalidade, precários e mal remunerados e que estão em desacordo com a legislação vigente. Dessa forma, os impactos do trabalho no nível global 
de pobreza são bastante reduzidos, se se considerar as implicações negativas que esse trabalho traz à vida de crianças e adolescentes. Principalmente, com relação à formação educacional, pois, além de não serem recuperados facilmente, há uma tendência à propagação entre gerações; por isso, a importância de se atrelar em todas as políticas de enfrentamento ao trabalho infantojuvenil a garantia à educação.

O que se percebe, a partir da pesquisa realizada, é que os atores sociais compartilham dos paradigmas construídos ao longo do tempo nas políticas voltadas à infância e adolescência no Brasil, e aqui não se trata de criticá-los ou procurar culpados, mas que se faz necessário uma atualização e atuação que esteja dentro dos parâmetros legais adotados. Considerando que nesta pesquisa boa parte dos participantes são professores e que informaram não ter conhecimento da temática e muito menos do enfrentamento no espaço escolar. Alberto (2012) afirma que o professor pode levar debates sobre o trabalho infantojuvenil com todo o corpo da escola, como também com as famílias trazendo o Conselho Tutelar, bem como outras instituições que fazem parte da rede de proteção sobre a legislação, as implicações, formas de combate e enfrentamento. É necessária uma atuação em rede, para que se consiga realizar o trabalho de enfrentamento e garantir os direitos.

\section{Conclusão}

A caracterização do trabalho infantojuvenil é feita aqui, a partir da visão dos atores sociais, de crianças e adolescentes em situação de trabalho e percepção do fenômeno. Apenas duas instituições, das seis, tinham dados referentes à temática em questão, justamente as instituições da assistência social, que figuram como responsáveis pelo enfrentamento. Isso se dá em virtude dos delineamentos das políticas de enfrentamento ao trabalho infantojuvenil na nossa sociedade, permeados de ideologias que foram construídas, ao longo do tempo, compartilhadas pela sociedade.

Foi possível identificar, a partir dos dados existentes nas duas instituições e da visão dos atores sociais, que o trabalho é feito em sua maioria por crianças e adolescentes que têm entre 11 e 16 anos de idade, afrodescendentes, nos mais diversos tipos, com predominância de vendas em locais públicos, como praças, ruas, praias, mercados, festas. Há também o trabalho em papelarias, supermercados, bares, restaurantes, oficinas, lava a jatos e atividades relacionadas ao trabalho agrícola, como capinar lotes, horta, limpar lotes. Ainda, segundo a percepção dos atores sociais, tais atividades até trazem riscos, mas o trabalho infantojuvenil é visto como bom, necessário, formador e dignificante. 
Apesar de minimizados pela percepção dos atores sociais, os riscos a que estão submetidos crianças e adolescentes em situação de trabalho são os mais diversos, por vezes ocultos e invisíveis, mas que trazem diversas implicações. Em todos os ramos de trabalho, existem as possibilidades de risco físico decorrente de danos ergonômicos irreversíveis pelo carregamento de peso excessivo, posturas inadequadas que podem lesionar a coluna e provocar deformações físicas interferindo na estrutura óssea, no peso e na altura da criança e do adolescente; a própria estrutura física, por vezes, acarreta dificuldades na realização de diversas atividades; sem contar os riscos biológicos de picadas de insetos e animais peçonhentos, os riscos de intoxicação e envenenamento por substâncias prejudiciais ao corpo humano, adultização precoce, com responsabilidades para além de sua capacidade cognitiva. Dificultam crianças e adolescentes passarem por todas as etapas da vida de forma tranquila e gradual, sendo retirado o tempo do brincar e do estudar, atraso no processo de escolarização, defasagem escolar, reprovação, repetência e abandono escolar.

Observa-se também que a transição da infância para a vida adulta para crianças e adolescentes de famílias pobres se dá de forma mais acelerada, ainda quando criança, que começam a trabalhar muito cedo. O trabalho infantojuvenil é uma das formas que permitem entreolhar e analisar a construção social da posição da infância e da adolescência na sociedade. Tal análise possibilita a compreensão de que essa é uma dimensão de classe social, de modo que há um grupo significante que continua exposto aos riscos do trabalho.

Segundo Lira (2016), as crianças por vezes não têm a real consciência do quanto são afetadas pelo trabalho e prejudicadas no seu desenvolvimento, não associando imediatamente as consequências sociais, psíquicas, escolares, físicas no corpo em decorrência do trabalho. Mas os dados permitem identificar, que o trabalho executado lhes retira um tempo precioso para brincar, para estudar, sobrecarregando o corpo em desenvolvimento com esforço físico além do tolerado, podendo representar prejuízos irreparáveis para a vida futura dessas crianças e adolescentes.

Percebe-se uma invisibilização do fenômeno no município devido à naturalização do mesmo, o que afeta diretamente no Sistema de Garantia de Direitos, o qual se torna falho por não ter registros formais nas instituições dos casos existentes e nem retirada dessas crianças e adolescentes da situação de trabalho, o que caracteriza uma grave violação de direito. Visto que as informações sobre o trabalho infantojuvenil, nessa pesquisa, se dá mais pela visão que os atores sociais têm, ao ver nas ruas crianças e adolescentes trabalhando, do que de dados que chegam até a instituição que atuam. Torna-se urgente a necessidade de ações para o combate 
ao trabalho infantojuvenil e desnaturalização do fenômeno por meio de conscientização e educação civil e políticas públicas efetivas que visem à real garantia de direitos das crianças e adolescentes do município.

Além do mais, o trabalho infantojuvenil é uma afronta aos direitos conquistados em prol das crianças e adolescentes, fere seu direito à educação, à saúde, à formação profissional, ao lazer, ao convívio familiar e comunitário, e a vivenciar a infância.

\title{
CHILDREN'S LABOUR AND LACK OF DATA: PERCEPTION OF THE PROTECTION NETWORK
}

\begin{abstract}
The objective of this paper is to identify the characteristics of child labour based on the protection network for the rights of children and adolescents. The research included 35 social actors who work in the Network for the protection of the rights of children and adolescents from a medium-sized city in the central region of Tocantins. A questionnaire composed of open and closed questions and for the analysis of the data the Bardin Thematic Analysis was used. From the data, most social actors answered that the institution they worked in did not have data on child and youth work, only two stated that they had child and youth work records, however, almost all social actors interviewed have seen or have knowledge of children and adolescents in work situations. A fact that draws attention is that most social actors consider child and youth work to be good, dignified and that allows children and adolescents to create responsibilities, as long as it does not interfere with studies and does not offer health risks.
\end{abstract}

Keywords: Child labour. Protection net. Rights of Children and Adolescents.

\section{TRABAJO INFANTIL Y FALTA DE DATOS: PERCEPCIÓN DE LA RED DE PROTECCIÓN}

\section{Resumèn}

Este artículo tiene como objetivo identificar las características del trabajo infantil y juvenil basado en la red de protección de los derechos de niños, niñas y adolescentes. Participaron en la investigación 35 actores sociales que trabajan en la Red para la protección de los derechos de niños, niñas y adolescentes de una ciudad mediana en la región central de Tocantins. Se utilizó un cuestionario compuesto por preguntas abiertas y cerradas y para el análisis de los datos se utilizó el Análisis temático de Bardin. A partir de los datos, la mayoría de los actores sociales respondieron que la institución en la que trabajaban no tenía datos sobre el trabajo infantil y juvenil, solo dos declararon que tenían registros de trabajo infantil y juvenil, sin embargo, casi todos los actores sociales entrevistados han visto o tienen conocimiento de los niños. y adolescentes en situaciones laborales. Un hecho que llama la atención es que la mayoría de los actores sociales consideran que el trabajo infantil y juvenil es bueno, digno y que permite a los niños y adolescentes crear responsabilidades, siempre que no interfiera con los estudios y no ofrezca riesgos para la salud.

Palabras clave: Trabajo infantil y juvenil. Red de protección. Derechos de niños, niñas y adolescentes. 


\section{REFERÊNCIAS}

ALBERTO, Maria de Fátima Pereira. Dimensão Subjetiva do Trabalho Precoce de Meninos e Meninas em Condição de Rua em João Pessoa (PB). 2002. 305f. Tese (Doutorado em

Sociologia) - Universidade Federal de Pernambuco, Recife, 2002.

. O estatuto da criança e do adolescente, o trabalho infantil e a escola. In: CALISSI, L.; SILVEIRA, R. M. G. (org.). O ECA nas Escolas: Perspectivas Interdisciplinares. João Pessoa: Editora Universitária da UFPB, 2012.

ALBERTO, M. F. P. et al. O trabalho infantil doméstico em João Pessoa. Brasília: OIT, 2005.

O trabalho infantil na rua. Cadernos de Psicologia Social do Trabalho, v. 13, n. 1, p. 59-71, 2010. Disponível em: http://pepsic.bvsalud.org/pdf/cpst/v13n1/v13n1a06.pdf. Acesso em: 23 mar. 2020.

ALBERTO, M. F. P.; SANTOS, D. P. Trabalho infantil e desenvolvimento: Reflexões à luz de Vigotski. Psicologia em Estudo, v. 16, n. 2, p. 209-218, 2011.

ALBERTO, M. F. P.; YAMAMOTO, O. H. Quando a Educação Não é Solução: Política de Enfrentamento ao Trabalho Infantil. Temas em Psicologia, v. 25, n. 4, 2017.

ARIÈS, Philippe. História Social da criança e da família. Tradução de Dora Flaksman. Rio de Janeiro: Zahar, 1995.

BARDIN, Laurence. Análise de conteúdo. São Paulo: Edições 70, 2010. 229 p.

BEHRING, E. R.; BOSCHETTI, I. Política social: Fundamentos e história. 9. ed. São Paulo, SP: Cortez, 2011.

BRASIL. Constituição da República Federativa do Brasil. Brasília: Casa Civil. 1988.

Disponível em:

https://www2.senado.leg.br/bdsf/bitstream/handle/id/518231/CF88_Livro_EC91_2016.pdf . Acesso em: 12 nov. 2012.

Decreto $n^{\circ}$ 6.481, de 12 de junho de 2008. Lista das Piores Formas de trabalho Infantil (lista TIP). 2008. Disponível em: http://www.planalto.gov.br/ccivil_03/_ato2007. Acesso em: 20 mar. 2020.

Decreto-Lei $\mathrm{n}^{\circ}$ 5.452, de 1 de maio de 1943. Aprova a consolidação das leis do trabalho. Lex: coletânea de legislação: edição federal, São Paulo, v. 7, 1943.

Estatuto da Criança e do Adolescente. Lei 8.069. Brasília: Secretaria Especial dos Direitos Humanos; Ministério da Educação, 1990.

Ministério do Desenvolvimento Social e Combate à Fome. Secretaria Nacional de Assistência Social. Tipificação Nacional de Serviços Socioassistenciais. Brasília: MDS, 2014. Disponível em:

http://www.mds.gov.br/webarquivos/publicacao/assistencia_social/Normativas/tipificacao.pdf Acesso em: 19 ago. 2015. 
CAMPOS, H. R.; ALVERGA, A. R. Trabalho infantil e ideologia: contribuição ao estudo da crença indiscriminada na dignidade do trabalho. Estudos de Psicologia, v. 6, n. 2, p. 227-233, 2001 .

DIAS, J. C.; ARAÚJO, G. S. O trabalho infantil na Região Norte do Brasil: Uma leitura a partir dos microdados do Censo Demográfico de 2010. Relatório Final. Brasília, 2013. Disponível em:

https://fnpeti.org.br/media/publicacoes/arquivo/O_Trabalho_Infantil_no_Brasil_com_Foco_n a_Regi\%C3\%A3o_Norte.pdf. Acesso em: 13 abr. 2020.

FALEIROS, V. P.; FALEIROS, E. S. Escola que protege: Enfrentando a violência contra crianças e adolescentes. 2. ed. Brasília, DF: Ministério da Educação, 2008.

FNPETI. Plano Nacional de Prevenção e Erradicação do Trabalho Infantil e Proteção ao Adolescente Trabalhador. Disponível em: http://www.fnpeti.org.br/biblioteca/ver/511conceito-de-trabalho-infantil.html. Acesso em: 14 fev. 2018.

IAMAMOTO, M. V. Questão social, família e juventude: Desafios do trabalho do assistente social na área sociojurídica. In: SALES, M. A.; MATOS, M.; LEAL, M. C. (org.). Política social, família e juventude. São Paulo, SP: Cortez, 2009. p. 261-298.

LIRA, T. S. O sentido do trabalho infantil doméstico: particularidades e contradições na esfera da reprodução social nas economias periféricas dependentes. 2016. 244f. Tese (Doutorado em Serviço Social) - Universidade Federal do Pernambuco, Recife, 2016.

MIOTO, Regina C. T. Família e Políticas Sociais. In: BOSCHETTI, Ivanete et al. (org.). Política Social no Capitalismo: Tendências Contemporâneas. São Paulo: Cortez, 2008. p.130148.

NASCIMENTO, Rafael Vieira Pires de. O que é a abordagem social no Suas? 2020.

Disponível em: https://www.gesuas.com.br/blog/abordagem-social/. Acesso em: 26 jun. 2020.

OLIVEIRA, R. C. S. Quero voltar para casa: O trabalho em rede e a garantia do direito à convivência familiar e comunitária para crianças e adolescentes que vivem em abrigo. 2. ed. São Paulo, SP: Associação dos Assistentes Sociais e Psicólogos do Tribunal de Justiça do Estado de São Paulo, 2010.

PNAD Contínua - Pesquisa Nacional por Amostra de Domicílios Contínua. Trabalho infantil, 2017. Disponível em:

https://biblioteca.ibge.gov.br/visualizacao/livros/liv101388_informativo.pdf. Acesso em: 12 maio 2020.

PILOTTI, Francisco; RIZZINI, Irene (org.). A Arte de Governar Crianças: a história das políticas sociais, legislação da assistência à infância no Brasil. Rio de Janeiro: Ed. Universitária Santa Úrsula, Armais Livraria e Editora, 2009.

RIZZINI, I. (coord.). Acolhendo crianças e adolescentes: Experiências de promoção do direito à convivência familiar e comunitária no Brasil. 2. ed. São Paulo, SP: Cortez, 2006. 
RIZZINI, I. O século perdido: Raízes históricas das políticas públicas para a infância no Brasil. São Paulo, SP: Cortez, 2008.

RODRIGUES, Jefferson Luiz Maciel. Trabalho infantil: Manual de atuação do Conselho Tutelar. Brasília: Ministério Público do Trabalho. Procuradoria do trabalho da $3^{\mathrm{a}}$ Região/MG, 2013.

SARTORI, E.; GARCIA, C. H. M. Políticas compensatórias x emancipatórias: desafios para implementação de programas de geração de renda. Rap, Rio de Janeiro, v. 46, n. 2, p. 425-52, mar./abr. 2012.

SILVA, Ana Cristina Serafim da. Meninas, exploração sexual comercial, corpo e subjetividade. Dissertação (Mestrado em Psicologia) 2009. Universidade Federal da Paraíba, João Pessoa, 2009.

SILVA, A. C. S.; PEREIRA, J. O trabalho infantojuvenil na agricultura no município de Tocantinópolis. Trabalho \& Educação, 22 (2) 55-69, 2013. Disponível em https://periodicos.ufmg.br/index.php/trabedu/article/view/9068/6525. Acesso em 13 de maio de 2019.

SILVA, A. C. S. \& ALBERTO, M. F. P. Exploração sexual comercial de crianças e adolescentes: A vivência subjetiva do corpo. Psicologia em Revista (Online), v. 22, p. 69-89, 2016. Disponível em: http://pepsic.bvsalud.org/scielo.php?script=sci_arttextepid=S167711682016000100006. Doi: http://dx.doi.org/DOI-10.5752/P.1678-9523.2016V22N1P69.

SILVA, Ana Cristina Silva., FONSECA, Jakeline Schneider. O Trabalho Infantojuvenil Informal de Rua na cidade de Tocantinópolis. In: FREIRE, J. S.E., SANTOS, J. B., FREIRE, J. C. S., Reflexões sobre Educação, Pobreza e Desigualdade Social: Primeiras aproximações. Palmas: EDUFT, 2017.

SILVA, Ana Cristina Serafim da. O trabalho infanto-juvenil em oficinas mecânicas e lava a jatos no Tocantins. Trabalho (Em) Cena, 3 (3) 100-114, 2018. DOI: 10.20873/25261487V3N3P100.

SILVA, Ana Cristina Serafim da; ALBERTO, M. F. (2019). Fios soltos da rede de proteção dos direitos das crianças e adolescentes. Psicologia: Ciência e Profissão, 39, 1-13. https://doi.org/10.1590/1982-3703003185358

VERONESE, Joseane Rose Petry; CUSTÓDIO, André Viana. Trabalho Infantil doméstico no Brasil. São Paulo: Ed. Saraiva, 2013.

Data de recebimento: 06/07/2020

Data de aceite: 08/09/2020

\section{Sobre as autoras:}

Ana Cristina Serafim Silva é Professora do curso de Psicologia da Universidade Federal do Tocantins- UFT, Doutora em psicologia Social pela Universidade Federal da Paraíba - UFPB. 
Coordenadora do Grupo de Estudos e Pesquisa sobre Infância e Adolescência - GEPIA. Endereço Eletrônico: anacris_serafim@uft.edu.br

Raimara Pereira Lourenço Duarte é Estudante do $9^{\circ}$ período do curso de Psicologia da Universidade Federal do Tocantins- UFT, membro do Grupo de Estudos e Pesquisa sobre Infância e Adolescência - GEPIA. Endereço Eletrônico: raimaralourenco10@gmail.com 